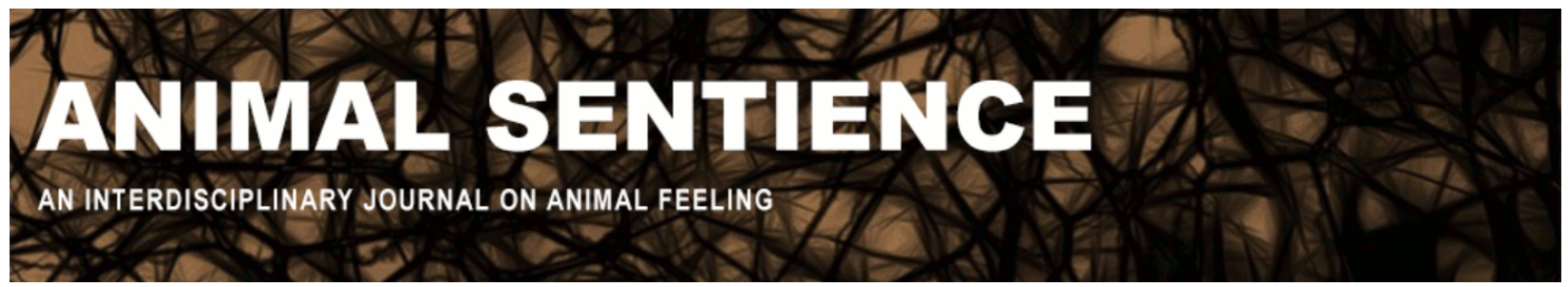

Guerra, Angel (2019) The ingenuity of cephalopods. Animal Sentience 26(5) DOI: $10.51291 / 2377-7478.1472$

Date of submission: 2019-05-31

Date of acceptance: 2019-06-05

(c) (i)




\title{
The ingenuity of cephalopods
}

Commentary on Mather on Octopus Mind

\author{
Angel Guerra \\ ECOBIOMAR, Instituto de Investigaciones Marinas (CSIC)
}

Abstract: I present a brief overview of the richness of cephalopod behavioral, neural and cognitive traits.

Angel Guerra, Department of Marine
Ecology \& Resources, Spanish National
Research Council, does research in
Ecology, Marine Biology and Systematics
(Taxonomy) on Cephalopod habitats in
ecosystem-based fisheries management.
Website

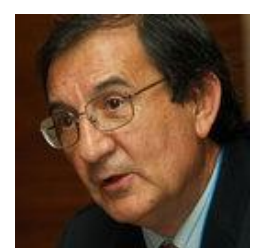

I agree with my colleague and friend Jennifer Mather (2019): "It is difficult to imagine what an animal as different from us as the octopus 'thinks,' but we can make some progress." She devotes a lot of to time studying the behavior of the marvelous animals that are the cephalopods and has done an excellent job. I will just try to shore up some of her results.

Cephalopods combine relatively simple nervous systems with complex and intriguing behaviors. They are mollusks that deploy a huge repertoire of tricks and devices to get what they want. "Live fast and die young" has become the most popular description of the lifestyle of cephalopods, but perhaps it would be more appropriate to say: "live fast and die young, but ingeniously."

The results obtained in elegant experiments, mainly with octopus and cuttlefish, show that some species display amazing forms of intelligence, comparable to those of many vertebrates. They highlight the ability of these animals - despite the brevity of their lives to manipulate objects; change shapes, colors and skin textures; escape from traps; mimic other animals or objects to defend against the predators, hunt or mate; learn and memorize; relate to their caregivers in the aquaria, and maybe even have fun playing. All this is achieved thanks to the development of excellent organs of the senses and a well-developed brain.

Cephalopods have a variety of sense organs that allow them to detect their various external stimuli. They also have appropriate effectors to execute responses to orders from their central nervous system (CNS). The locomotors allow jet propulsion, hunting, evasion into the water and gliding out of it, as well as slow and stabilized swimming. They also have several buoyancy mechanisms. The suckers and hooks of the arms and tentacles serve mainly to grip prey in hunting strategies, but also in defensive tactics. In addition, they can serve as secondary sexual characters. The buccal mass contains a chitinous spout, the main radula, sometimes a secondary radula, and the salivary glands: a whole device perfectly designed to tear prey apart or to pierce other mollusk shells. Through the muscles of their mantle and arms, cephalopods achieve changes in the texture of their skin. They also experience chromatic changes thanks to the chromatophores, iridophores and leucophores. All these skin adaptations allow crypsis and aposematism (Stevens \& Merilaita 2008). Many cephalopods have the ability to emit light (bioluminescence) from the photophores. Another effective evasion strategy is the expulsion of ink. 
The CNS of cephalopods is the most complex of all invertebrates. The relationship between brain and body volume is greater in them than in most of fish, amphibians and reptiles. Apart from the nautiluses, the rest of the cephalopods present a large brain, protected by a cartilaginous skull. The brain is divided into two regions: subesophageal and supraoesophageal. It is highly organized and made up of numerous lobes that can reach up to 40. The best-known brain is that of the common octopus (Octopus vulgaris), with around 170 million neurons, $76.3 \%$ of them housed by the two huge optical lobes. The subesophageal lobes contain $1.5 \%$ and control the activity of the muscles of the viscera, the mantle, the arms and the tentacles, as well as those surrounding the chromatophores. The supraesophageal lobes, with $21.8 \%$ of the neurons, are involved in the response to chemotactic stimuli from the arms and from the mouth, and also manage exploratory actions, learning and memory. Finally, the magnocellular lobe, which contains 0.40 percent of the neurons, is an intermediate motor center that manages defense and escape reactions. The system of giant nerve fibers originates in the magnocellular lobe of the Decapodiformes (cuttlefish and squid).

A very characteristic feature of cephalopods is the great importance of the peripheral nervous system. The network of local brachial modules (NLBM) seems to act as a semiautonomous system of behavior generation. This perspective clarifies some aspects of the capacity of the arms to exercise different functions. The assumption that the octopus has two brains (the one forming the lobes enclosed in the skull and the NLBM) is open to discussion, and plays an important role in what is meant by "brain" and by "cognition." Despite this controversy, there is no doubt that the NLBM constitutes an outstanding system. Moreover, the best-known peripheral system is that of the giant axons, which give rise to the incomparable hydrodynamic invention of jet propulsion. On the other hand, there are two memory storage processes: one short-term, the other long-term. Both types of memory differ structurally and functionally, but both are complementary and necessary.

Some experiments in aquaria have shown the existence of embryonic visual learning in the invertebrates. Such cognitive abilities seem to confer important adaptive advantages in the processing and acquisition of information about foods available after hatching. Another feature that has been observed in the embryos of cephalopods is motor and perceptual laterality. The ontogenesis of lateralization seems to depend on the interaction between genes and experience.

Among the cephalopods are animals with greater and more dynamic expressive and mimetic capacity. The paradigm of this ingenuity is the mimic octopus Thaumoctopus mimicus, which is able to mimic the appearance and movements of more than fifteen species of its habitat.

Do cephalopods play? In addition to the behaviors briefly described above, cephalopods can display peculiar behaviors without an apparent function. It seems that, for various reasons, some cephalopod species do have ludic behaviour.

Individual behaviors appear that allow us to distinguish one individual from another. These traits have led some ethologists to use the term "personality." However, to avoid ambiguity and inaccuracy, I prefer to use the term "personhood," as defined by the Spanish philosopher Xavier Zubiri (1986) in his book Sobre el Hombre, "The genetic constituent of everything living being whereby, in addition to physico-chemical traits, there are already present all their psychological traits, such as the capacity for sentience and cognition."

The quest to understand the nervous system, behavior and intelligence of cephalopods offers many very stimulating challenges. Promising recent findings are opening new doors in ethology, neuroscience and the study of biomimetic techniques. 


\section{References}

Amodio, P. M., Boeckle, A. K., Schnell, L. Ostojíc, G., Fiorito, \& Clayton, N. S. 2019. Grow smart and die young: Why did cephalopods evolve intelligence? Trends in Ecology and Evolution, 34(1), 45-56.

Darmaillacq, A. S., Dickel, L., \& Mather, J. (eds.). 2014. Cephalopod cognition. Cambridge University Press.

Guerra, A. 2019. El ingenio de los cefalópodos. Investigación y Ciencia, 48.

Hanlon R. T., \& Messenger, J. B. 2018. Cephalopod behaviour. Cambridge University Press.

Mather, J. 2019. What is in an octopus's mind? Animal Sentience 26(1).

Nixon, M., \& Young, J. Z. 2003. The brains and lives of cephalopods. Oxford University Press.

Norman, M. D., Finn, J., \& Tregenza, T. 2001. Dynamic mimicry in an Indo-Malayan octopus.

Proceedings of the Royal Society B, 268, 1755-1758.

Stevens, M., \& Merilaita, S. (2008). Animal camouflage: Current issues and new perspectives. Philosophical Transactions of the Royal Society B: Biological Sciences, 364(1516), 423427.

Zubiri, X. (1986). Sobre el hombre. $1^{\text {a }}$ ed., a cargo de Ignacio Ellacuría. 